\title{
Studies of Natural Soil Radioactivity in the Kirchhoff Hill (the Leningrad Region, the Russian Federation)
}

\author{
S. V. Lebedevㄹ, I. I. Podlipskiy², S. V. Dubrova, ${ }^{2, *}$, P. S. Zelenkovskiy', and S. G. \\ Kamenkova $^{1}$ \\ ${ }^{1}$ Saint Petersburg State University, 7/913B Universitetskaya Emb., 199034, St Petersburg, Russia \\ ${ }^{2}$ The Herzen State Pedagogical University of Russia, 48 Moika Emb., 191186, St. Petersburg, \\ Russia
}

\begin{abstract}
From the geoecological point of view, a special place in the geological section of the Kirchhoff Hill is occupied by highly radioactive geological bodies - dictyonema oil shales. As a result of glacial tectonic dislocations and due to numerous local elevations and depressions in the relief, dictyonema oil shales can come into direct contact with the soil over relatively large areas here. Based on the results of the route survey of the gamma field over the soils of the Kirchhoff Hill in the zone of anomalously high exposure dose rate, we laid a pit. Seven samples were taken and analyzed from the depth of 0 to $85 \mathrm{~cm}$. The first two samples $(0-$ $25 \mathrm{~cm}$ ) correspond to the gray-humus dark-profile soil on dictyonema oil shales type. Here, the average value of the specific effective activity (Aeff) makes $1,750 \mathrm{~Bq} / \mathrm{kg}$. The average Aeff of the next 5 samples of dictyonema oil shales $(25-85 \mathrm{~cm})$ makes $1,870 \mathrm{~Bq} / \mathrm{kg}$. Such radioactivity values belong to the environmental hazard class IV and impose significant restrictions on building and construction in the area of studies.
\end{abstract}

\section{Introduction}

The Kirchhoff Hill is a part of the Duderhof Heights (the Duderhof Hill and the Kirchhoff Hill united by a common base, are located at absolute elevations of 90-100 m), and it is located in the Leningrad Region on the border with St. Petersburg. It contrasts sharply with the surrounding monotonous plain, representing an exceptional formation for the region of the Izhora Plateau in geomorphological and geological terms. The conditions of occurrence, thickness and outlook of the rocks that make up the Kirchhoff Hill, are anomalous for the surrounding area. Thus, usually the dip of beds in the region of the Izhora Plateau is monoclonal, and it is measured in minutes. In this place, the rocks of the Cambrian and Ordovician periods are inclined at angles up to $70^{\circ}$, with the very variable dip azimuth. The amplitude of the upheaval of the overlying bed of the Siverskiy clays of the Cambrian period and overlying rocks reaches $100 \mathrm{~m}$. What calls attention to itself is the strong erosion of clays and compartmentalization of limestones. The thickness of quaternary

\footnotetext{
*Corresponding author: dubrova.stanislav@gmail.com
} 
deposits in this region usually does not exceed several meters, while here it reaches $80 \mathrm{~m}$ $[1,2]$.

\section{Materials and methods}

The main source of natural radionuclides (NRN) and, consequently, of ionizing radiation is represented by the rocks containing ${ }^{238} \mathrm{U},{ }^{235} \mathrm{U},{ }^{232} \mathrm{Th},{ }^{40} \mathrm{~K}$ (the highest content is observed in acidic (granites) and alkaline rocks). Because of radioactive decay, they form uranium, actinuranium and thorium series, respectively. It should be noted that one of the daughter products of the uranium series is radon, a radioactive gas that has no color and odor and poses a danger to human health.

The radioactivity of soils depends on the radioactivity of the parent rock materials. Thus, Th remains in undisturbed rock remnants and tends to accumulate. $U$, on the other hand, can be easily carried out. The elements of the biosphere, in turn, are capable of accumulating Ra. In small quantities, radioactive elements are present in living organisms.

In the period from 2017 to 2019, the equivalent dose rate (EDR) was measured over the soils of the Kirchhoff Hill in the Lomonosov District of the Leningrad Region, the Russian Federation.

The exposure dose rate in $\mathrm{mcR} / \mathrm{h}$ was measured with an SRP-97 radiometer. Scintillation geological exploration devices SRP-97 are meters of the exposure dose rate of $\gamma$-radiation. The measurement range of the exposure dose rate (EDR) of gamma radiation of the Ra226 radionuclide is from 0 to $309 \mathrm{mcR} / \mathrm{h}$.

On the site with an area of 209.7 hectares, a route gamma survey was carried out. The site covers the southeastern, highest peak of the Kirchhoff Hill (up to $176 \mathrm{~m}$ ) and the part of its northwestern, southern and southeastern steep (up to $41^{\circ}$ ) slopes. The scale of the survey makes 1:10,000.

The SRP-97 survey radiometer was used in the audio signal listening mode to detect areas with increased gamma background. At the same time, whenever possible, we tried to ensure continuous listening when the radiometer moved along straight or Z-shaped routes. The EDR readings were recorded in the log at control points separated from each other at distances of 50-150 m. The step of fixed measurements depended on the absolute EDR values and the nature of the gamma field variability.

In accordance with MU 2.6.1.2398-08 "Radiation Control and Sanitary and Epidemiological Assessment of Land Plots for the Construction of Residences, Buildings and Structures for Public and Industrial Purposes in Terms of Ensuring Radiation Safety" guidelines [3], if the results of gamma survey reveal zones in which the dose rate of gamma radiation exceeds $0.3 \mathrm{mcSv} / \mathrm{h}$ on land plots for the construction of residential and public buildings, or $0.6 \mathrm{mcSv} / \mathrm{h}$ on land plots for the construction of industrial buildings and structures, then such zones should be considered as anomalous. It should be noted that the value of the equivalent dose rate of $0.3 \mathrm{mcSv} / \mathrm{h}$ for gamma radiation corresponds to the exposure dose rate of $31 \mathrm{mcR} / \mathrm{h}$, and that of $0.6 \mathrm{mcSv} / \mathrm{h}$ - to the exposure dose rate of 62 $\mathrm{mcR} / \mathrm{h}[1,2]$. Therefore, when developing a map of the gamma field for the delineation of the anomalous zones, we selected precisely these boundaries of the classification intervals 31 and $62 \mathrm{mcR} / \mathrm{h}$.

\section{Results and Discussion}

The Kirchhoff Hill is about $4 \mathrm{~km}$ by $1.5 \mathrm{~km}$. The maximum absolute elevation of about 170 $\mathrm{m}$ is located near its southwestern tip. The hill is characterized by a sharp contrasting relief with a fresh look. The top of the hill is flattened. However, the slopes closest to the summit 
are cut by couloirs with slope angles of the sides from $20^{\circ}$ to $40^{\circ}$ ( $2 \%$ of the mountainous area). According to our relief computer modeling data, the foot of the hill can be determined by the contour with an absolute elevation of $108 \mathrm{~m}$. Above this contour, smooth slopes with an angle of inclination of up to $5^{\circ}$ make up $68 \%$ of the mountainous area, and steeper slopes with an angle of inclination from $5^{\circ}$ to $20^{\circ}$ make up $30 \%$ from the total area of the hill.

There are no natural exposures on the hills. There are only a few mostly abandoned quarries with a depth of up to 3-4 m. Along the border of the highway passing by the southern foot of the Kirchhoff Hill, a section of a slope is exposed to a depth of about 1.5 $\mathrm{m}$. In most workings, limestones crushed to a state of landwaste come out on the daylight surface. Where the limestones are more monolithic, they can be observed steeply dipping. Moreover, in different places there are some small isolated shows of obolus sandstones, dictyonema oil shales and blue Cambrian clays. Poor exposure in combination with difficult conditions of occurrence opens up wide opportunities for various interpretations of the nature of the Duderhof dislocations. To explain their origin, the following main hypotheses were put forward - tectonic hypothesis, hypothesis of clay diapirism, glacial tectonic hypothesis. The glacial tectonic hypothesis is supported by most of the researchers who have worked in the area. There is a significant variability of occurrence elements at short distances, a strong fragmentation of limestones, a confinedness of disturbances to the edge of a clint, and their close relationship with the moraine containing a large number of erratic masses.

The study and comparison of the sections of the down holes located at small distances from each other, imply the complexity of the structure of the Duderhof Heights. At the same time, significant differences are noted in the hypsometric position of the same bedding rocks, and, moreover, violation of the normal rock sequence and presence of the moraine under the Paleozoic displacements. The glacial deposits themselves have a significant thickness. They represent the local moraine or glacial breccias very often.

From the geoecological point of view, a special place in the geological section of the Kirchhoff Hill is occupied by the dictyonema oil shales, the thickness of which reaches 3.5 meters. These are highly radioactive geological bodies that determine the radiation situation in the Leningrad Region along the entire length of the Balto-Ladoga clint [1, 2].

The diktyonema oil shales belong to the Koporye suite of the Pakerort bedding rock. This is the second from the bottom strata of the Ordovician deposits, developed within the Leningrad Region. The shales got their name from the characteristic fossil dendroid graptolite Dictyonema flabelliformis.

Based on the results of studies of one of the exposures in the area of the Kirchhoff Hill, we come to the conclusion that the average uranium content in the rock makes $240 \mathrm{~g} / \mathrm{t}$. At the same time, $20 \%$ of the studied samples show that the uranium content exceeds $300 \mathrm{~g} / \mathrm{t}$. Thus, we can really speak about the presence of highly radioactive rocks with the uranium commercial content corresponding to poor rocks in the geological section of the Kirchhoff Hill.

Most often, the dictyonema oil shales are overlain by later sediments, but there are areas, mainly confined to the Balto-Ladoga clint, where highly radioactive rocks are located to the daylight surface.

The modern period of soil formation on the territory of the Leningrad Region started after the melting of the ice sheet about 12 thousand years ago [1]. As a result of glacial tectonic dislocations and due to numerous local elevations and depressions of the relief, dictyonema oil shales in the area of the Kirchhoff Hill can contact directly with the soil over relatively large areas $[4,5]$. Here, dispersion halos of natural radionuclides can be formed naturally due to mechanical or chemical enrichment of soils with radioactive elements contained in bituminous mudstones. Two types of soils located on the Kirchhoff 
Hill are formed on dictyonema oil shales, and they are considered to be obsolescent. These are gray-humus dark-profile soil on dictyonema oil shales and dark-humus dark-profile soil on the eluvium of dictyonema oil shales.

In the places of direct contact of dictyonema oil shales with soil, the increased level of gamma field should be expected. This assumption was confirmed by the results of the route gamma survey of the site. The exposure dose rate was measured in $\mathrm{mcR} / \mathrm{h}$ with the help of an SRP-97 radiometer. In total, 219 observation points were used in the interpretation of the survey data. Within the area of studies, the EDR values vary from 11 to $125 \mathrm{mcR} / \mathrm{h}$. The site covers the top of the hill and a part of its southwestern slope. The boundaries of the site coincide with the outlines of the projected Luge and Bobsleigh Complex as a part of the Tuutari Alpine Skiing Zone.

In total, seven anomalous zones are shown up where the EDR makes more than 31 $\mathrm{mcR} / \mathrm{h}$, with their total area of 39 hectares (18.6\% of the area of the entire site). In accordance with the MU 2.6.1.2398-08 guidelines [3], this area is not suitable for the construction of residential and public buildings due to the relatively high level of radioactivity in soils. To describe the soil developed on the dictyonema oil shales, an $85 \mathrm{~cm}$ deep pit was prepared on the western slope, at the point where the EDR value of $105 \mathrm{mcR} / \mathrm{h}$ was recorded.

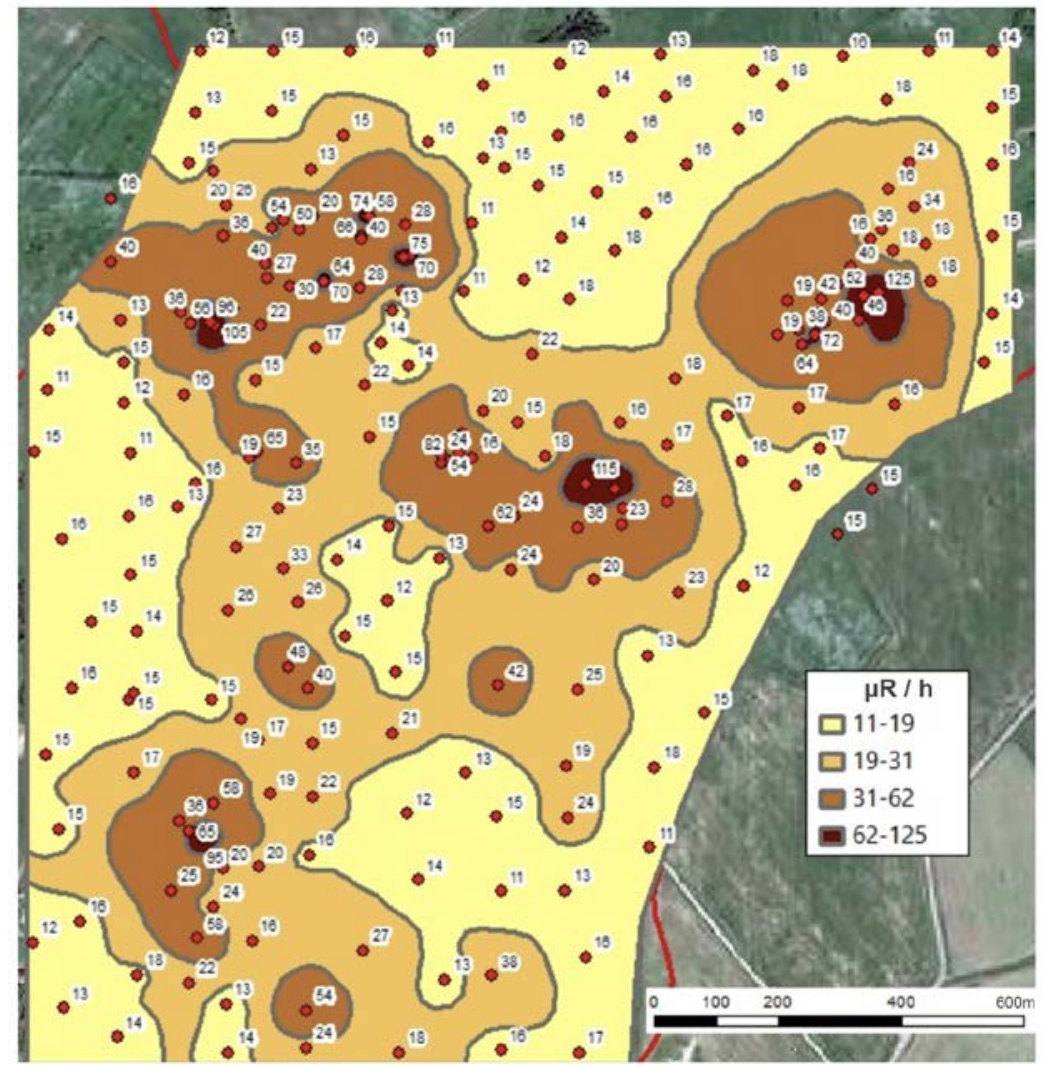

Fig. 1. Exposure Dose Rate Map (mcR/h) over the Soils of the Kirchhoff Hill.

On the summit and western slope of the Kirchhoff Hill, an anomalous zone of 14.2 hectares (27\% of the total investigated area) is distinguished, where the exposure dose rate (DER) exceeds $31 \mathrm{mcR} / \mathrm{h}$. In accordance with the MU 2.6.1.2398-08 guidelines [3], this area is not suitable for the construction of residential and public buildings due to the 
relatively high level of radioactivity in soils. Here, three anomalous zones with the total area of 0.7 hectares were found, where the EDR exceeds $62 \mathrm{mcR} / \mathrm{h}$. These sites are no longer suitable not only for the construction of residential and public buildings, but also for industrial facilities.

At the point with the highest EDR value, we laid a $85 \mathrm{~cm}$ deep pit. The description of section along the vertical wall of the pit is given in the following table.

Table 1. Description of Section along the Wall of the Pit.

\begin{tabular}{|c|c|}
\hline $\begin{array}{l}\text { Bedding } \\
\text { Rock }\end{array}$ & Description \\
\hline \multirow[t]{2}{*}{$\begin{array}{l}\text { AY } \\
0-25 \mathrm{~cm}\end{array}$} & $\begin{array}{l}\text { Gray, recent, comminuted, from sandy loam to slightly argillaceous, loose crumb } \\
\text { structure with elements of granularity due to coprolites of earthworms, compacted, } \\
\text { inclusion of roots of herbaceous meadow plants up to } 15 \% \text {, bubbles up, cliff edge with } \\
\text { the next bedding rock, straight edge, no light mineral grains, admixture of poorly } \\
\text { decomposed plant residues }\end{array}$ \\
\hline & $\begin{array}{l}15-25 \mathrm{~cm} \text {, differs from the previous one in a denser composition and the presence of } \\
\text { lenses of greenish clay loam }\end{array}$ \\
\hline \multirow[t]{3}{*}{$\begin{array}{l}\text { Cca } \\
25-85 \mathrm{~cm}\end{array}$} & $\begin{array}{l}\text { Cross beds of slightly altered dictyonema bituminous oil shales }-25-30 \mathrm{~cm} \text {, greenish- } \\
\text { gray, recent, fissile, lamelliferous, compacted, slightly argillaceous, dense carbon- } \\
\text { bearing aggregates, bubbles up, cliff edge, straight edge }\end{array}$ \\
\hline & $\begin{array}{l}\text { 30-75 cm, dark-gray, fissile, light joint faces, compacted, dense carbon-bearing } \\
\text { aggregates, bubbles up, recent, cliff edge, straight edge }\end{array}$ \\
\hline & $\begin{array}{l}\text { 75-85 cm, dark-gray dictyonema oil shales, heavily argillaceous, no inclusions and mud } \\
\text { bands, lamelliferous }\end{array}$ \\
\hline
\end{tabular}

Thus, the section consists of soil and dictyonema oil shales. The soil can be defined as gray-humus dark-profile soil on dictyonema oil shales. Such soils are considered to be obsolescent (1 CR category) and are listed in the Leningrad Region Red Book of Soils. The soil profile consists of a low-thickness gray-humus bedding rock lying directly on the slightly altered layers of dictyonema oil shales, represented by soils of different color (from dark-gray to brown) and coarseness of grading (from sandy loam to heavy argillaceous).

Seven samples were taken and analyzed from the depth of 0-85 cm. In accordance with the description of the section, the first two samples $(0-25 \mathrm{~cm})$ are represented by darkprofile gray-humus soil. The next five samples (in depth) correspond to dictyonema oil shales located close to the surface at the site of the section.

Soil/rock samples taken in the field were dried, then, if necessary, crushed to a fraction $<3 \mathrm{~mm}$. The specific activity of the samples was determined with the help of the RADEK installation in the testing laboratory of Radiation Hygiene Department of the Center of Hygiene and Epidemiology in St. Petersburg Federal State Healthcare Institution. According to the laboratory analyzes, the specific activity of natural radionuclides (radium226, thorium-232, potassium-40) was determined, and the specific effective activity of rocks (Aeff) was also calculated. The results of the research are shown in Figure 2. 


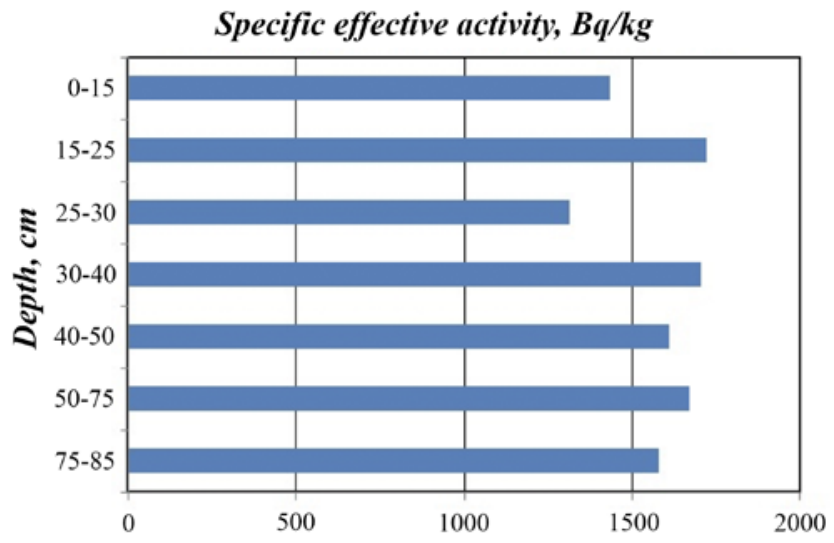

Fig. 2. Distribution of Soil/Rock Radioactivity along the Depth of the Cut.

The average value of the specific effective activity (Aeff) for soil $(0-25 \mathrm{~cm})$ makes $1,575 \mathrm{~Bq} / \mathrm{kg}$. The average Aeff of the next five samples of dictyonema oil shales also makes $1,575 \mathrm{~Bq} / \mathrm{kg}$. It should also be noted that the radioactivity of the layer of dictyonema oil shales at a depth of $25-30 \mathrm{~cm}$ is somewhat reduced. This layer is also distinguished concerning the description of the rock. Apparently, it is depleted in radioactive elements due to their mechanical removal or chemical corrosion with simultaneous accumulation in the soil.

According to the Aeff value, 5 samples out of 7 belong to class IV of environmental hazard $1,500 \leq$ Aeff $\leq 4,500 \mathrm{~Bq} / \mathrm{kg}$ [6,7], which implies significant restrictions during construction and the need for additional measures to ensure the environmental safety of the population.

The specific activity of soil/rock radionuclides in $\mathrm{Bq} / \mathrm{kg}$ can be converted into the absorbed dose in air in nano-Grays per hour (nGy/h) according to the coefficients adopted in the documents of the UN Scientific Committee on the Effects of Atomic Radiation [8]. The conversion factors for 226Ra, 232Th, 40K are 0.462, 0.604, and 0.0417 respectively.

Dose rate, $n G y / h$

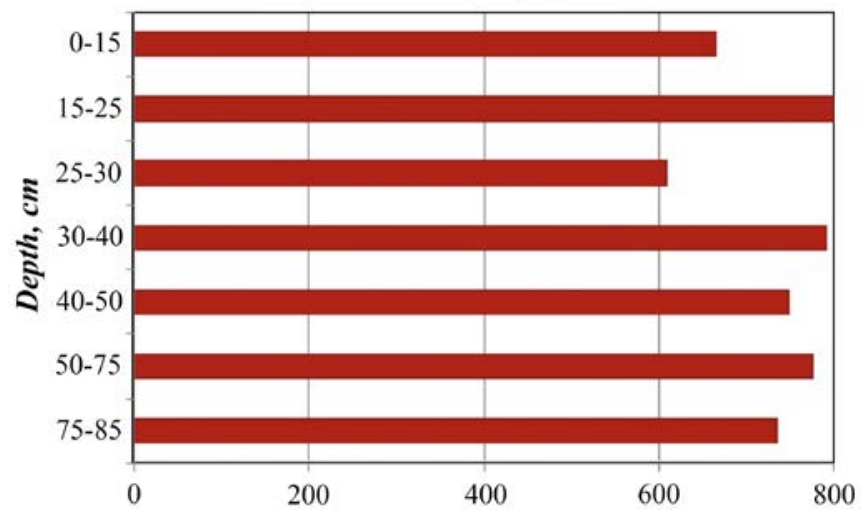

Fig. 3. Estimated Absorbed Dose Rate for Studied Rocks

Figure 3 shows the estimated dose rate data absorbed in the air. For the soil, the dose makes $730 \mathrm{nGy} / \mathrm{h}(85 \mathrm{mcR} / \mathrm{h})$. The average dose generated by dictyonema oil shales also makes $730 \mathrm{nGy} / \mathrm{h}$. 


\section{Conclusions}

In general, the estimated data correspond to the results of measurements of the exposure dose rate obtained in this place with the help of the SRP-97 device (90-105 mcR/h).

As a comparison, we can cite the data on the absorbed dose rate over soils in the countries closest to the Leningrad Region, where the daylight radioactive rocks are also observed [8]: Estonia - $59 \mathrm{nGy} / \mathrm{h}$ with a range of values from 14 to $230 \mathrm{nGy} / \mathrm{h}$; Finland $71 \mathrm{nGy} / \mathrm{h}$ with a range of values from 45 to $139 \mathrm{nGy} / \mathrm{h}$; Sweden - the average absolute value of the dose rate makes $56 \mathrm{nGy} / \mathrm{h}$ with a range of values from 40 to $500 \mathrm{nGy} / \mathrm{h}$. For the whole territory of Russia, the average absolute value of the dose rate makes $65 \mathrm{nGy} / \mathrm{h}$, with values varying from 12 to $102 \mathrm{nGy} / \mathrm{h}$. Thus, the values of the absorbed dose rate over the soils of the Kirchhoff Hill can be 10-12 times higher than the average values for Russia and the countries closest to the Leningrad Region.

\section{References}

1. S. V. Lebedev, S.V. Dubrova, P.V. Fedorov, V.V. Kurilenko, W. Siabato SPbU Bull. Earth Sc. 63,2 (2018)

2. S. V. Lebedev, S.V. Dubrova, P.V. Fedorov, W. Siabato, V.V. Kurilenko SPbU Bull. Earth Sc. 65,1 (2020)

3. MU 2.6.1.2398-08 «Radiation Monitoring and Sanitary-Epidemiological Assessment of Land Plots for the Construction of Residential Buildings, Public and Industrial Buildings and Structures in Terms of Ensuring Radiation Safety», Federal Service for Supervision in the Sphere of Consumer Protection and Human Well-Being, Moscow (2008)

4. R.E. Dashko, Ya.A. Karpova J. Min. Inst. 206 (2004)

5. S. Dubrova , S. Chelinho, P. Zelenkovskiy, I. Podlipskiy E3S Web Conf. 169 (2020)

6. NRB-99/2009, Radiation Safety Regulations. Hygienic Regulations and Standards (Sanitary Rules and Norms 2.6.1.2523-09/2009) (Ministry of Healthcare of the Russian Federation, Moscow, 2009)

7. OSPORB-99/2010, Basic Sanitary Rules of Radiation Safety (Sanitary Rules 1.2.6.1.2612-10) (Ministry of Healthcare of the Russian Federation, Moscow, 2010)

8. UNSCEAR, United Nations Scientific Committee on the Effects of Atomic Radiation, Report to the General Assembly, with scientific annexes. Volume I: Sources, Annex B: Exposures from Natural Radiation Sources (United Nations Publications, New York, 2000) 